\title{
Characterization of Fusarium oxysporum f. sp. loti Forma Specialis nov., a Monophyletic Pathogen Causing Vascular Wilt of Birdsfoot Trefoil
}

\author{
Michael J. Wunsch, Alexandra H. Baker, David W. Kalb, and Gary C. Bergstrom, Department of Plant Pathol- \\ ogy and Plant-Microbe Biology, Cornell University, 334 Plant Science, Ithaca, NY 14853 USA
}

\begin{abstract}
Wunsch, M. J., Baker, A. H., Kalb, D. W., and Bergstrom, G. C. 2009. Characterization of Fusarium oxysporum $\mathrm{f}$. sp. loti forma specialis nov., a monophyletic pathogen causing vascular wilt of birdsfoot trefoil. Plant Dis. 93:58-66.

Fusarium wilt, a vascular wilt caused by Fusarium oxysporum, has been a serious problem for birdsfoot trefoil (Lotus corniculatus) production in parts of New York and Vermont since the 1970 s, causing wilt, severe root necrosis, and rapid plant death. Analysis of F. oxysporum isolates causing this disease indicated that the pathogen has a unique host range relative to previously designated $F$. oxysporum formae speciales and is monophyletic. Pathogenic isolates from New York and Vermont caused severe vascular wilt of trefoil and moderate vascular wilt of pea but no disease on alfalfa, red clover, soybean, or dry bean. The host range of trefoil isolates was distinct from $F$. oxysporum isolates pathogenic to other legumes. F. oxysporum isolates pathogenic to trefoil belonged to a single vegetative compatibility group separate from nonpathogenic isolates and shared identical mitochondrial small subunit rDNA, translation elongation factor 1alpha, and nuclear rDNA intergenic spacer haplotypes. Phylogenetic analysis of the concatenated sequence data assigned isolates pathogenic to trefoil to a single, well-supported clade distinct from other pathogenic $F$. oxysporum. We propose designating the fungus Fusarium oxysporum Schlechtendahl emend. Snyder \& Hansen f. sp. loti forma specialis nova.
\end{abstract}

Fusarium wilt, caused by Fusarium oxysporum, has been a serious problem for birdsfoot trefoil (Lotus corniculatus L.; BFT) production in parts of New York and Vermont since the 1970s. BFT is a forage legume valued for its production of condensed tannins (49), which prevent bloat and improve the efficiency of protein utilization in ruminant animals (27), and for its adaptation to soils and field conditions poorly suited for alfalfa production $(14,22,26)$. Through the early 1970 s, BFT was widely planted in the Champlain Valley of New York and Vermont for the production of certified seed, and BFT continues to be planted in New York and Vermont for forage production. Reduced persistence of BFT contributed to a sharp reduction in acreage planted to BFT in the Champlain Valley in the 1970s and early 1980s (36), and problems with rapid stand decline continue to limit BFT production in New York and Vermont $(11,33,50 ; \quad M$. J. Wunsch, personal observation). In affected fields, BFT seedlings display chlorosis, stunting and wilting, severe vascular discoloration, and plant death within weeks of planting. Vascular tissues of infected plants

Corresponding author: Gary C. Bergstrom E-mail: gcb3@ cornell.edu

Accepted for publication 22 September 2008.

doi:10.1094/PDIS-93-1-0058

(C) 2009 The American Phytopathological Society are colonized by $F$. oxysporum, which is readily isolated from both roots and stems, and high rates of BFT mortality are observed in the seeding year $(21,36,50)$. Fusarium wilt has certain similarities to a Fusarium root and crown rot of BFT described in Argentina and Uruguay $(1,13)$ but progresses more rapidly. The disease prevalent in South America is also characterized by vascular wilt and severe root necrosis caused by $F$. oxysporum, but the wilt symptoms develop more slowly, with significant plant mortality not observed until the second and third production years $(2,3)$. Fusarium wilt is distinct from general root and crown rot of BFT $(8,16)$, which is associated with a complex of pathogens, including various Fusarium species, and does not lead to vascular wilt. Fusarium wilt of BFT is only known to occur in New York and Vermont.

F. oxysporum is a ubiquitous fungus in both agricultural and nonagricultural soils worldwide (19). It can colonize plant debris, but it is generally found in close association with plant roots (55). F. oxysporum can colonize roots endophytically without causing disease symptoms, colonize roots pathogenically and contribute to root and crown rot, or colonize the vascular system and cause severe root necrosis, vascular wilt, and rapid plant death $(5,20,53)$. Isolates causing vascular wilt are hostspecific, causing disease on only one to several plant species and colonizing other species endophytically or not at all $(5,20)$. Pathogenic $F$. oxysporum isolates differing in host range are morphologically indistinguishable and are organized into specialized forms, or formae speciales, on the basis of the host(s) on which they cause vascular wilt (5).

Bergstrom and Kalb (9) proposed that the Fusarium wilt pathogen of BFT found in New York be designated a new forma specialis, F. oxysporum f. sp. loti. No previously designated formae speciales are known to have a host range encompassing BFT (6), and preliminary greenhouse experiments with a single monoconidial isolate from New York suggested the pathogen was specific to BFT. However, host range experiments were not repeated, and the proposed taxonomic designation could not be finalized.

Management of Fusarium wilt of BFT has been limited by a lack of resistant cultivars. A greenhouse evaluation of five commercially available BFT cultivars indicated that all were highly susceptible to Fusarium wilt (57). Likewise, field and greenhouse trials conducted in the 1990s indicated that widely planted Norcen and 11 other BFT cultivars available to growers all exhibited high susceptibility to Fusarium wilt (10). A cultivar with moderate resistance to Fusarium wilt was released in 2004 (52), and efforts to breed BFT with improved resistance to Fusarium wilt are ongoing. The breeding efforts, however, have utilized a single pathogenic isolate to screen for resistance, and the appropriateness of this protocol has not been evaluated. Many formae speciales of $F$. $o x$ ysporum are composed of two or more clonal evolutionary lineages $(7,34,39,46)$, and clonal lineage is closely related to pathogenic race in multiple formae speciales of $F$. oxysporum $(28,34,42,46)$. Because races differ in their virulence to specific host genotypes, use of a single pathogenic isolate to breed for resistance is only appropriate when multiple races of the pathogen are not present. The genetic diversity of the pathogen causing Fusarium wilt of BFT has not been evaluated, and it is unclear whether the BFT pathogen is composed of a single or multiple evolutionary lineages across its known geographic distribution. If multiple evolutionary lineages are present, differences in pathogenic properties among the isolates are more likely, and the use of multiple isolates, one from each lineage, may be needed to screen for host resistance. 
The objectives of this study were to evaluate whether the Fusarium wilt pathogen of BFT warrants designation as a forma specialis nova and to assess the genetic diversity of the pathogen population across the pathogen's known geographic distribution. Replicated host range experiments were conducted to assess the taxonomic designation of the BFT pathogen; the forma specialis concept in $F$. $o x$ ysporum is based on unique host range, and cross-inoculation experiments utilizing multiple hosts and multiple formae speciales of F. oxysporum are required to demonstrate that a Fusarium wilt pathogen warrants designation as a forma specialis nova (5). Vegetative compatibility group (VCG) analysis (15) and multilocus sequence typing (MLST) were conducted to evaluate the genetic diversity of the BFT pathogen population. Both techniques have proven useful for identifying clonal lineages of $F$. oxysporum $(7,31,34,40)$. MLST analysis was conducted using three loci widely used in intraspecific studies of $F$. $o x$ ysporum $(34,39,40)$ : the complete intergenic spacer (IGS) of the nuclear rDNA repeat, an intron-spanning region of the translation elongation factor 1-alpha (EF$1 \alpha$ ), and the mitochondrial small subunit rDNA (mtSSU). For illustrative purposes, the MLST data were combined with publicly available sequences generated by previous researchers and presented as a phylogeny; maximum parsimony was used for phylogenetic inference.

\section{MATERIALS AND METHODS}

$F$. oxysporum isolates used in this study. F. oxysporum cultures isolated from symptomatic BFT in 1985, 1990, 1991, 1995, and 2004 were utilized in this study. Cultures were either isolated directly from symptomatic BFT collected in commercial production fields or baited from naturally infested field soil. Twenty-one BFT production fields were evaluated for symptomatic BFT, and soil samples were collected from an additional four fields with a history of BFT production. Baiting was conducted by seeding the susceptible BFT cultivar Georgia-1 (Deer Creek Seed, Ashland, WI) into a mix of field soil and autoclaved sand $(1: 1, \mathrm{vol} / \mathrm{vol})$ in greenhouse flats and evaluating plants for vascular wilt weekly for 8 weeks. F. oxysporum isolates were collected from BFT throughout the known geographic distribution of the Fusarium wilt pathogen in New York and Vermont. Monoconidial cultures were established from each isolate and assessed for morphological characteristics on carnation leaf agar (CLA) and for gross cultural characteristics on potato dextrose agar (PDA; Difco Laboratories, Becton, Dickson and Co., Sparks, MD); cultures were grown 7 days (on PDA) or 14 days (on CLA) at approximately $25^{\circ} \mathrm{C}$ under a mix of fluorescent cool-white and ultraviolet light (12 h/day).
Pathogenicity trial. All singleconidium cultures identified as $F$. $o x$ ysporum were assessed for pathogenicity to BFT in the greenhouse. Individual trefoil plants (cv. Georgia-1) were established in cells of greenhouse flat inserts (806 narrow series deep insert; Hummert International, Earth City, MO) in a 1:2:1 mix (by volume) of peat moss, autoclaved sand, and autoclaved loam soil. Three to four seeds were placed in each pot, and seeds were covered with approximately $0.1 \mathrm{~g}$ of Rhizobium inoculant for birdsfoot trefoil (Trace Chemicals LLC, Pekin, IL). Three weeks after seeding, plants were thinned to one plant per pot. Plants were grown at approximately 25 to $35^{\circ} \mathrm{C}$ in the greenhouse under $16 \mathrm{~h}$ of light/day and fertilized monthly with a $200 \mathrm{ppm}$ solution of 21-520 fertilizer (364 g/gal) and Epsom salts (113 g/gal). Plants were inoculated 12 to 13 weeks after seeding using a procedure adapted from pathogenicity assays developed for other $F$. oxysporum wilt pathogens $(12,41,51)$. Inoculum was prepared by growing cultures in Czapek-Dox broth (C-Dox; Difco Laboratories, Becton, Dickson and Company, Sparks, MD) on a rotating shaker (150 rpm) for 3 to 4 days and passing the cultures through two layers of cheesecloth. Foliage was trimmed approximately $6 \mathrm{~cm}$ above the crown, plants were removed from the pots, and the root mass (complete with its associated soil) was severed 4 to $5 \mathrm{~cm}$ below the crown. The lower portion of the root mass was returned to the pots, the upper portion was soaked for $30 \mathrm{~min}$ in a conidial suspension adjusted to $1 \times 10^{6}$ spores $/ \mathrm{ml}$ or in a water or dilute C-Dox (1:3 C-Dox to water, $\mathrm{vol} / \mathrm{vol}$ ) control, and plants were repotted. In every replicate of the experiment, 64 unique isolates and two control treatments were assessed, and each treatment was evaluated on 12 plants. The experiment was repeated three times. The spatial organization of treatments was randomized within each replicate. Plants were assessed for wilting, chlorosis, and stunting once to twice weekly after repotting. Stems of symptomatic plants were collected at least $1 \mathrm{~cm}$ above the crown, stripped of leaves, surface-sterilized in $0.6 \%$ hypochlorite and $70 \%$ ethanol, cut into segments, and plated onto 1/4-PDA. Cultures growing from the ends of stem segments and displaying gross morphological characteristics typical of $F$. oxysporum were transferred to a modified Nash-Snyder Fusarium-selective media (FSM) prepared as described by Nelson et al. (37) but with 0.3 g/liter streptomycin sulfate and $0.175 \mathrm{~g} /$ liter neomycin sulfate. A plant was considered positive for Fusarium wilt only if cultures isolated from the ends of stem segments grew on FSM. Fourteen weeks after inoculation, plants were uprooted, and the first $4 \mathrm{~cm}$ of each plant's taproot was split longitudinally to evaluate root necrosis. Necrosis was rated on a scale of 0 to 4: 0 , no discol- oration of stele; 1, small dark specks or strands in the stele ( 0.1 to $33 \%$ of stele necrotic); 2 , moderate to large dark strands forming arcs or rings in the stele crosssection (33.1 to $66 \%$ of stele necrotic); 3 , extensive discoloration of the stele (66.1 to $99 \%$ of stele necrotic); 4 , stele completely necrotic and plant dead (100\% necrosis). Isolates were considered pathogenic to trefoil if they caused Fusarium wilt in at least two of the three replicates of the experiment and were considered nonpathogenic if they failed to cause Fusarium wilt in any replicate.

Host range. Cross-inoculations were conducted in the greenhouse with economically important legumes grown in New York and, when available, corresponding pathogenic $F$. oxysporum strains. Birdsfoot trefoil (cv. Georgia-1; Deer Creek Seed, Ashland, WI), red clover (Trifolium pretense cv. Chesapeake; $\mathrm{H}$. Riday, USDA Dairy Research Center, Madison, WI), alfalfa (Medicago sativa cv. MNGN1; USDA Western Regional Plant Introduction Station, Pullman, WA), soybean (Glycine max cv. Essex; K. Rainey, Virginia Tech, Blacksburg, VA), pea (Pisum sativum cv. M410; Brotherton Seed, Moses Lake, WA), and bean (Phaseolus vulgaris cv. U.I. 114; S. Singh, University of Idaho Research and Extension Center, Kimberly, ID) were tested. All cultivars have documented susceptibility to $F$. oxysporum $(12,32,44,45,51)$. One isolate each of $F$. oxysporum f. sp. medicaginis (Fom004 from Pennsylvania), $F$. oxysporum f. sp. pisi (Fopi001 from New York), and F. oxysporum pathogenic to red clover (Fo062 from Wisconsin), and five $F$. oxysporum isolates pathogenic to BFT, including isolates from both New York (Fo012, Fo069, and FoMK61) and Vermont (FoVt3a and FoVt71), were evaluated. Dilute C-Dox broth (1:3 C-Dox to water, vol/vol) was used as a control. Individual plants were established in SC10 Cone-Tainers $(3.8 \mathrm{~cm}$ diameter, $21 \mathrm{~cm}$ deep; Stuewe and Sons, Inc., Corvallis, OR) in a 1:2:1 mix (by volume) of peat moss, autoclaved sand, and autoclaved loam soil. Three to four seeds were placed in each pot, and seeds were covered with approximately $0.1 \mathrm{~g}$ of the appropriate Rhizobium inoculant (Trace Chemicals LLC). One to three weeks after seeding, plants were thinned to one plant per pot. A $200 \mathrm{ppm}$ solution of 21-5-20 fertilizer (96 g/liter) and Epsom salts (30 g/liter) was applied monthly. The plants were grown in the greenhouse at approximately 25 to $35^{\circ} \mathrm{C}$ under $16 \mathrm{~h}$ of light/day.

Protocols specific to each host were used for inoculations (12,18,32,41,51). Spore suspensions were established with C-Dox broth, as described above. Individual trefoil, alfalfa, clover, bean, pea, and soybean plants were inoculated with spore suspensions $\left(1 \times 10^{6}\right.$ spores $\left./ \mathrm{ml}\right)$ and the CDox control 12 weeks, 10 weeks, 6 weeks, 
10 days, 10 days, and 8 days after seeding, respectively. Planting dates were coordinated such that inoculations of the different hosts were conducted concurrently in each replicate of the experiment. Prior to inoculation, foliage was trimmed approximately 8 to $10 \mathrm{~cm}$ above the crown for alfalfa, clover, and trefoil but not trimmed for pea, bean, or soybean. Plants were removed from their pots, and the lower third to quarter of the roots were removed. Soil was shaken free of alfalfa, clover, pea, bean, and soybean but not trefoil roots. Trefoil, alfalfa, and clover were soaked in spore suspensions or the C-Dox control for $30 \mathrm{~min}$; bean and soybean plants, for 5 min; and pea plants, for 1 to $2 \mathrm{~min}$. Twelve plants of each host species were subjected to each treatment in each replicate of the experiment; the experiment was repeated three times. The spatial organization of treatments within each replicate was randomized.

Plants were assessed for wilting, chlorosis, and stunting once to twice weekly after repotting. Stems of symptomatic plants were collected at least $1 \mathrm{~cm}$ above the crown, surface-sterilized, and assessed for F. oxysporum, as conducted during pathogenicity testing (above). A plant was considered positive for Fusarium wilt only if cultures isolated from the ends of stem segments grew on FSM. Root necrosis was evaluated 65 days after inoculation by splitting the taproot of each plant longitudinally. Necrosis was rated on a scale of 0 to 5: 0 , no root necrosis; 1 , small dark specks or strands in the stele $(0.1$ to $10 \%$ necrosis); 2, moderate dark strands forming small arcs or rings in the stele crosssection (10.1 to $35 \%$ necrosis); 3, large dark strands in the stele ( 35.1 to $65 \%$ necrosis); 4, most of stele discolored (65.1 to $90 \%$ necrosis); 5 , stele and part or all of cortex discolored and/or plant dead (90.1 to $100 \%$ necrosis).

Statistical analysis. To evaluate the incidence of Fusarium wilt of inoculated versus control treatments in the host range experiment, contingency tables were constructed for the binary wilt response across hosts and treatments within each experimental replicate. Heterogeneity chi-square analysis (56) resulted in a failure to reject the null hypothesis that the replicates of the experiment were homogeneous $\left(\chi^{2}=\right.$ 105.87, df $=105, P=0.457$ ), and results were pooled across replicates. The proportion of wilted plants was calculated for each treatment, and the proportions were arcsine transformed (56). The transformed data were analyzed with the Dunnett test for multiple comparisons, except that rather than comparing all treatments to each other, only comparisons between the control (C-Dox) and the inoculated treatments were made (56).

Root necrosis data were analyzed with cumulative logistic regression (23). Heterogeneity chi-square analysis (56) re- sulted in a rejection of the null hypothesis that experimental replicates were homogeneous $\left(\chi^{2}=335.62\right.$, df $=256, P=0.0006$, pathogenicity testing experiment; $\chi^{2}=$ $587.01, \mathrm{df}=525, P=0.0312$, host range experiment), and results were not pooled across replicates. Logistic regression was conducted controlling for the effect of experimental replicate. Individual contrasts of pairs of treatments were performed with Wald chi-square tests. In the pathogenicity testing experiment, contrasts were established between the C-Dox control and each of 32 other treatments (28 pathogenic isolates, 3 nonpathogenic isolates, and the water control). In the host range experiment, contrasts were established between the C-Dox control and each inoculated treatment for each host. All analyses were implemented in PROC GENMOD (SAS, version 9.1, SAS Institute, Cary, NC). The Bonferroni multiple comparison procedure (38) was used to control the Type I error rate at the level of the experiment across the 32 contrasts conducted in the pathogenicity testing experiment and the 48 contrasts conducted in the host range experiment.

Vegetative compatibility. Nitrogen nonutilizing (nit) mutants were produced as previously described $(15,43)$ for $31 \mathrm{~F}$. oxysporum isolates: 28 isolates pathogenic to trefoil and three isolates (FoChz10c, FoStL1a, and FoVal42) obtained from trefoil but nonpathogenic to trefoil (Table 1). Reciprocal pairwise crosses were established on minimal media between nitl and NitM mutants for nine of the isolates: six pathogenic isolates (Fo036, Fo068, FoMK41, FoPlc14a, FoVH17a, and FoVt63) and three nonpathogenic isolates (FoChz10c, FoStL1a, and FoVal42). Tester NitM strains were selected representing each unique vegetative compatibility group identified in the reciprocal crosses, and nit 1 mutants of the remaining 22 pathogenic trefoil isolates were crossed with each tester strain.

DNA extraction, amplification, purification, and sequencing. $F$. oxysporum isolates were grown 7 days at room temperature on 1/4-PDA, transferred to $50-\mathrm{ml}$ centrifuge tubes containing $35 \mathrm{ml}$ of halfstrength potato dextrose broth (1/2-PDB; 12 g PDB/liter water), and placed on a rotary shaker $(150 \mathrm{rpm})$ for 4 to 5 days. The mycelium was harvested by centrifuging, decanting the broth, and rinsing twice in sterile distilled water (adding $35 \mathrm{ml}$ of water, centrifuging, and decanting). The rinsed mycelium was lyophilized, and DNA was extracted using a DNeasy Plant Mini Kit (Qiagen Inc., Valencia, CA) according to manufacturer's instructions.

The complete nuclear ribosomal DNA intergenic spacer (IGS) region and portions of the nuclear elongation factor $1-\alpha$ (EF$1 \alpha)$ and mitochondrial small subunit rDNA (mtSSU) were amplified and sequenced for 37 isolates. Three isolates (FoChz10c,
FoStL1a, and FoVal42) obtained from trefoil but nonpathogenic to trefoil, all 28 isolates identified as pathogenic to trefoil (Table 1), two isolates (Fom001 and Fom004) of $F$. oxysporum f. sp. medicaginis, two isolates (Fopi001 and Fopi002) of $F$. oxysporum f. sp. pisi, one isolate (Fo062) of F. oxysporum pathogenic to red clover (Trifolium pratense), and one isolate (FoGa2) of $F$. oxysporum $\mathrm{f}$. sp. tulipae were analyzed. Pathogenicity testing of isolates Fom001, Fom004, Fopi001, Fopi002, and Fo062 resulted in rapid wilt and severe root necrosis on the corresponding hosts (Tables 2 and 3; M. J. Wunsch, unpublished data). Amplification of EF- $1 \alpha$ was conducted in $50-\mu$ reactions containing $3 \mu$ of template DNA, $1 \times$ Takara Ex Taq buffer (Takara Bio, Madison, WI), $200 \mu \mathrm{M}$ each of dATP, dCTP, dGTP, and dTTP, $0.5 \mu \mathrm{M}$ each of primers EF1a and EF2ag (39), and 1.25 units Ex Taq DNA polymerase, hot start version (Takara Bio). PCR was conducted in a PTC-100 Peltier Thermal Cycler (MJ Research, Waltham, MA) as follows: $30 \mathrm{~s}$ at $95^{\circ} \mathrm{C}, 30$ $\mathrm{s}$ at $60^{\circ} \mathrm{C}$, and $1 \mathrm{~min}$ at $72^{\circ} \mathrm{C}$ for 40 cycles, followed by a 5 -min extension at $72^{\circ} \mathrm{C}$ and a $4^{\circ} \mathrm{C}$ bath. Amplification of mtSSU was conducted in $50-\mu l$ reactions with $3 \mu \mathrm{l}$ of template DNA, 1× Takara Ex Taq buffer, $100 \mu \mathrm{M}$ each of dATP, dCTP, dGTP, and dTTP, $0.3 \mu \mathrm{M}$ each of primers MS1 and MS2 (54), and 1.25 units Ex Taq DNA polymerase, hot start version. Thermocycling parameters were 40 cycles of $94^{\circ} \mathrm{C}$ for $35 \mathrm{~s}, 52^{\circ} \mathrm{C}$ for $55 \mathrm{~s}$, and $72^{\circ} \mathrm{C}$ for 2 min, followed by a 7-min extension at $72^{\circ} \mathrm{C}$ and a $4{ }^{\circ} \mathrm{C}$ bath. Amplification of the IGS region was conducted in $25-\mu \mathrm{l}$ reactions with $1.5 \mu$ of template DNA, 1× Takara Ex Taq buffer, $100 \mu \mathrm{M}$ each of dATP, dCTP, dGTP, and dTTP, $0.3 \mu \mathrm{M}$ each of primers LR11 (5'-TGGTTTTTG CGGCTGTCTGA-3') and CNS3 (54), and 0.625 units Ex Taq DNA polymerase, hot start version. Thermocycling parameters were $90 \mathrm{~s}$ at $94^{\circ} \mathrm{C}$ and 35 cycles of $94^{\circ} \mathrm{C}$ for $30 \mathrm{~s}, 72.5^{\circ} \mathrm{C}$ for $30 \mathrm{~s}$, and $73.5^{\circ} \mathrm{C}$ for 3 min $40 \mathrm{~s}$, followed by a 6-min extension at $73.5^{\circ} \mathrm{C}$ and a $4^{\circ} \mathrm{C}$ soak. To ensure sufficient PCR product for sequencing, five 25$\mu \mathrm{l}$ reactions amplifying the IGS region were conducted for each isolate and pooled prior to PCR product purification. Negative controls (no template) were included in every assay. Amplification products were visualized under UV light on $1.5 \%$ agarose gels stained with ethidium bromide. PCR products were purified with a QIAquick PCR Purification Kit (Qiagen Inc.) according to manufacturer's instructions. Sequencing was conducted at the Cornell University Life Sciences Core Laboratories Center (Ithaca, NY). The amplification primers were used to sequence EF-1a and mtSSU, and primers CLR12 (4), CNS1 (54), ONL13B (O'Donnell 1994), IGS 2r (5'-CACCAG CCAAACCACCTCTTC- $3^{\prime}$ ), and IGS $3 \mathrm{c}$ 
(5'-TCCGAGACCGTTTTAGTGGGCC-3') were used to sequence the IGS region. Trace files were visualized with FinchTV (Geospiza, Seattle, WA), and sequences were edited in EditSeq (Lasergene 7.2.1, DNASTAR Inc., Madison, WI). The edited sequences were deposited in GenBank under accession numbers EU313430 to EU313540. Additional mtSSU, EF-1 $\alpha$, and IGS sequences of other Fusarium isolates generated by Mbofung et al. (34), Baayen et al. (7), and K. O'Donnell (USDA-ARS, Peoria, IL) were obtained from GenBank or directly from K. O'Donnell.

Phylogenetic analysis. Sequences were aligned with Clustal W in MegAlign (Lasergene 7.2.1, DNASTAR) using default gap and gap length parameters of 15.00 and 6.66, respectively. Alignments were manually edited to resolve inconsistencies in the alignment of individual regions of sequence. The edited sequence alignment has been deposited in TreeBASE.

Unweighted parsimony analysis was conducted with PAUP* version $4.0 \mathrm{~b} 10$ (47). Heuristic searches for the most par- simonious trees were conducted with 1,000 random addition replicates and tree bisection with reconnection branch swapping. Gaps were treated as missing data, and trees were rooted with $F$. subglutinans based on previous phylogenetic analysis (34). Clade stability was assessed with 1,000 bootstrap replicates. Bootstrap analysis was implemented with a heuristic search in PAUP* using 1,000 random addition sequences per replicate and tree bisection with reconnection branch swapping. To reduce computational time, rearrangements per bootstrap replicate were limited to 10,000 . Congruence of the mtSSU, EF$1 \alpha$, and IGS data partitions was assessed with the Kishino-Hasegawa (KH) and Templeton Wilcoxon signed rank (WS-R) tests in PAUP* using $70 \%$ bootstrap majority trees from each partition as constraints. The $\mathrm{KH}$ test indicated that all partitions were congruent except mtSSU and IGS $(P<0.001$ constraining $\mathrm{mtSSU}$ to the IGS bootstrap tree). The WS-R test indicated that the EF- $1 \alpha$ and IGS partitions were congruent $(P=0.2482$ con- straining EF-1 $\alpha$ to the IGS bootstrap tree, $P=0.0402$ constraining IGS to the EF- $1 \alpha$ bootstrap tree) but that the EF- $1 \alpha$ and IGS partitions were incongruent with the mtSSU partition $(P<0.02)$. However, incongruence was limited to the placement of taxa distantly related to isolates pathogenic to BFT; isolates pathogenic to BFT were placed in a single, well-supported clade ( $>70 \%$ bootstrap support) in all $\mathrm{mtSSU}, \mathrm{EF}-1 \alpha$, and IGS most parsimonious trees (MPTs), and all taxa placed in a separate clade from the BFT isolates in the MPT of the mtSSU partition were placed in separate, well-supported clades in the MPTs of the EF- $1 \alpha$ and IGS partitions. Consequently, mtSSU, EF-1 $\alpha$, and IGS sequences were concatenated, and global parsimony analysis of the three loci was conducted.

\section{RESULTS}

F. oxysporum isolates. Twenty-eight $F$. oxysporum isolates causing vascular wilt and severe root necrosis of BFT were collected (Table 1). The isolates were ob-

Table 1. Geographic origin, vegetative compatibility group, and pathogenicity of Fusarium oxysporum isolates from birdsfoot trefoil used in this study

\begin{tabular}{|c|c|c|c|c|c|}
\hline \multirow[b]{2}{*}{ Isolate $^{b}$} & \multirow[b]{2}{*}{ Origin (year isolated) } & \multirow[b]{2}{*}{$\mathrm{VCG}^{\mathrm{c}}$} & \multicolumn{2}{|c|}{ Pathogenicity $^{\mathbf{a}}$} & \multirow[b]{2}{*}{ Designation $^{d}$} \\
\hline & & & Wilt & Necrosis & \\
\hline Fo012 & Wyoming Co., NY (1990) & 0480 & $8 / 36$ & $1.31 * * *$ & Fusarium oxysporum f. sp. loti \\
\hline Fo036 & Essex Co., NY (1985) & 0480 & $2 / 36$ & $0.81 *$ & F. oxysporum f. sp. loti \\
\hline Fo054 & Wyoming Co., NY (1991) & 0480 & $3 / 36$ & $1.08 * * *$ & F. oxysporum f. sp. loti \\
\hline Fo055 & Wyoming Co., NY (1991) & 0480 & $3 / 36$ & $0.75 *$ & F. oxysporum f. sp. loti \\
\hline Fo068 & Wyoming Co., NY (1995) & 0480 & $5 / 36$ & $1.22 * *$ & F. oxysporum f. sp. loti \\
\hline Fo069 & Wyoming Co., NY (1995) & 0480 & $12 / 36$ & $1.50 * * * *$ & F. oxysporum f. sp. loti \\
\hline Fo070 & Wyoming Co., NY (1995) & 0480 & $4 / 36$ & $1.32 * * *$ & F. oxysporum f. sp. loti \\
\hline Fo071 & Wyoming Co., NY (1995) & 0480 & $5 / 36$ & $1.20 * *$ & F. oxysporum f. sp. loti \\
\hline Fo072 & Wyoming Co., NY (1995) & 0480 & $7 / 36$ & $1.28 * * *$ & F. oxysporum f. sp. loti \\
\hline FoFT1a & Wyoming Co., NY (2004) & 0480 & $7 / 36$ & $1.17 * * *$ & F. oxysporum f. sp. loti \\
\hline FoFT3a1 & Wyoming Co., NY (2004) & 0480 & $11 / 36$ & $1.37 * * * *$ & F. oxysporum f. sp. loti \\
\hline FoGF3c & Tompkins Co., NY (2004) & 0480 & $5 / 36$ & $1.33 * * * *$ & F. oxysporum f. sp. loti \\
\hline FoMK41 & Wyoming Co., NY (2004) & 0480 & $4 / 36$ & $1.39 * * * *$ & F. oxysporum f. sp. loti \\
\hline FoMK61 & Wyoming Co., NY (2004) & 0480 & $9 / 36$ & $1.65 * * * *$ & F. oxysporum f. sp. loti \\
\hline FoMK7b1 & Wyoming Co., NY (2004) & 0480 & $7 / 36$ & $1.31 * * *$ & F. oxysporum f. sp. loti \\
\hline FoPlc1b & Wyoming Co., NY (2004) & 0480 & $4 / 36$ & $1.28 * * *$ & F. oxysporum f. sp. loti \\
\hline FoPlc14a & Wyoming Co., NY (2004) & 0480 & $4 / 36$ & $1.06 * *$ & F. oxysporum f. sp. loti \\
\hline FoVH52 & Wyoming Co., NY (2004) & 0480 & $2 / 36$ & $0.89 * *$ & F. oxysporum f. sp. loti \\
\hline FoVH7c1 & Wyoming Co., NY (2004) & 0480 & $6 / 36$ & $0.86 *$ & F. oxysporum f. sp. loti \\
\hline FoVH17a & Wyoming Co., NY (2004) & 0480 & $7 / 36$ & $1.65 * * * *$ & F. oxysporum f. sp. loti \\
\hline FoVt3a & Addison Co., VT (2004) & 0480 & $2 / 36$ & $1.08 * * *$ & F. oxysporum f. sp. loti \\
\hline FoVt63 & Addison Co., VT (2004) & 0480 & $7 / 36$ & $1.09 * * *$ & F. oxysporum f. sp. loti \\
\hline FoVt71 & Addison Co., VT (2004) & 0480 & $7 / 36$ & $1.17 * * *$ & F. oxysporum f. sp. loti \\
\hline FoVt81 & Addison Co., VT (2004) & 0480 & $2 / 36$ & $1.06 * *$ & F. oxysporum f. sp. loti \\
\hline FoVt112b & Addison Co., VT (2004) & 0480 & $4 / 36$ & $1.20 * * *$ & F. oxysporum f. sp. loti \\
\hline FoVt12b & Addison Co., VT (2004) & 0480 & $4 / 36$ & $0.81 *$ & F. oxysporum f. sp. loti \\
\hline FoVt14 & Addison Co., VT (2004) & 0480 & $2 / 36$ & $0.58 \mathrm{NS}$ & F. oxysporum f. sp. loti \\
\hline FoVt17a & Addison Co., VT (2004) & 0480 & $4 / 36$ & $1.03 * *$ & F. oxysporum f. sp. loti \\
\hline FoChz10c & Clinton Co., NY (2004) & Unique & $0 / 36$ & $0.08 \mathrm{NS}$ & F. oxysporum \\
\hline FoStL1a & St. Lawrence Co., NY (2004) & Unique & $0 / 36$ & $0.11 \mathrm{NS}$ & F. oxysporum \\
\hline FoVal42 & Columbia Co., NY (2004) & Unique & $0 / 36$ & $0.03 \mathrm{NS}$ & F. oxysporum \\
\hline
\end{tabular}

a Proportion of plants exhibiting Fusarium wilt within 98 days of inoculation and mean root necrosis of plants 98 days after inoculation in a replicated greenhouse experiment with the susceptible birdsfoot trefoil cultivar Georgia-1. The root mass was cut 4 to $5 \mathrm{~cm}$ below the crown and soaked 30 min in a suspension of $1.0 \times 10^{6}$ spores/ml. Two control treatments, water and dilute Czapek-Dox broth, were included. Plants were only considered positive for Fusarium wilt if Fusarium sp. was reisolated from surface-sterilized sections of symptomatic stems collected at least $1 \mathrm{~cm}$ above the crown. Root necrosis was rated on a 0 to 4 scale: 0 , no root necrosis; 1 , small dark specks or strands in the stele; 2 , moderate to large dark strands forming arcs or rings in the stele cross-section; 3, extensive discoloration of the stele; 4, stele completely necrotic and plant dead. Asterisks represent a significant difference relative to the control $(P<0.05, P<0.01, P<0.001$, and $P<0.0001$ for one, two, three, and four asterisks, respectively); "NS" represents no significant difference $(P$ $>0.05$ ) relative to the control. Of the 36 plants subjected to each control treatment, none developed vascular wilt, and mean root necrosis was 0.06 .

b All isolates were obtained from roots or stems of birdsfoot trefoil.

c "Unique" indicates that the isolate is vegetatively compatible with itself but with none of the other isolates listed.

${ }^{\mathrm{d}}$ All isolates designated $F$. oxysporum f. sp. loti caused Fusarium wilt in one or more of 12 plants in at least two of the three replicates of the experiment assessing pathogenicity. 
tained throughout the pathogen's known geographic distribution, with 17 from western New York (Wyoming County), one from central New York (Tompkins County), one from eastern New York (Essex County), and eight from western Vermont (Addison County). The isolates were collected from eight fields in Wyoming County, one field in Tompkins County, one field in Essex County, and one field in Addison County. Isolates from two fields in Wyoming County and one field in Addison County were obtained by baiting the pathogen from naturally infested field soil. All other isolates were obtained directly from symptomatic BFT collected in production fields. Wilt symptoms, including flagging, chlorosis, and stunting, generally developed within 20 and 60 days of inoculation. Wilt incidence (Table 1), however, was low to moderate because applications of MilStop (BioWorks, Inc., Victor, NY) to control powdery mildew led to death of mildew-infected leaves and stems, making wilt symptom diagnosis difficult. Root necrosis was elevated relative to the control at the conclusion of the experiment, 98 days after inoculation (Table 1). Nonpathogenic isolates (isolates that did not induce vascular wilt of BFT) did not cause root necrosis (Table 1). No wilt symptoms developed in either the water or the C-Dox broth control, and mean root necrosis was 0.06 in both controls.

Cultural and morphological characteristics of the isolates fit the type description of $F$. oxysporum (37). On PDA, isolates produced abundant aerial mycelia with peach colored sporodochia. The underside of colonies was cream to peach colored. On CLA, isolates produced slightly curved macroconidia with a boot shaped basal cell and attenuated apical cell that were generally three-septate but occasionally two- or four-septate. Microconidia were oval or kidney shaped and generally single celled but occasionally two-celled. Microconidia were borne in false heads on monophialides. Chlamydospores were terminal or intercalary, mostly single but occasionally in pairs.

Host range. The $F$. oxysporum isolates pathogenic to BFT displayed a unique host range relative to the other pathogenic $F$. oxysporum tested. Of the five $F$. oxysporum isolates pathogenic to BFT tested, all caused moderate to high incidence of vascular wilt on BFT, low incidence of vascular wilt on peas, and no vascular wilt on alfalfa, red clover, bean, or soybean (Table 2). The incidence of vascular wilt on BFT was significantly different from the control $(P<0.01)$ for all five isolates; the incidence of vascular wilt on pea, however, was significantly different from the control $(P<0.05)$ for only one isolate

Table 2. Incidence ${ }^{a}$ of Fusarium wilt on agriculturally important legumes grown in New York after inoculation with Fusarium oxysporum isolates from birdsfoot trefoil, alfalfa, red clover, and pea

\begin{tabular}{|c|c|c|c|c|c|c|c|c|c|}
\hline \multirow[b]{2}{*}{ Host $^{\mathbf{b}}$} & \multicolumn{5}{|c|}{ F. oxysporum f. sp. loti } & \multirow{2}{*}{$\begin{array}{c}\begin{array}{c}\text { F. oxysporum } \\
\text { f. sp. medicaginis }\end{array} \\
{\text { Fom } 004^{\mathrm{d}}}\end{array}$} & \multirow{2}{*}{$\begin{array}{c}\text { F. oxysporum } \\
\text { red clover }\end{array}$} & \multirow{2}{*}{$\begin{array}{c}\begin{array}{c}\text { F. oxysporum } \\
\text { f. sp. pisi }\end{array} \\
\text { Fopi001 }^{\mathrm{d}}\end{array}$} & \multirow[b]{2}{*}{ Control $^{\mathrm{e}}$} \\
\hline & FoVt3a ${ }^{c}$ & FoVt71 ${ }^{\mathrm{c}}$ & FoMK61 ${ }^{\mathrm{c}}$ & Fo069' & Fo012 $^{c}$ & & & & \\
\hline Trefoil & $44.4 * *$ & $52.8 * *$ & $58.3 * *$ & $58.3 * *$ & $63.9 * *$ & 0 & 0 & 2.8 & 0 \\
\hline Alfalfa & 0 & 0 & 0 & 0 & 0 & $97.2 * *$ & 0 & 0 & 2.8 \\
\hline Red clover & 0 & 0 & 0 & 0 & 0 & 0 & $19.4 *$ & 0 & 0 \\
\hline Pea & 2.8 & 8.3 & $19.4 *$ & 11.1 & 11.1 & 2.8 & 11.1 & $97.2 * *$ & 0 \\
\hline Bean & 0 & 0 & 0 & 0 & 0 & 0 & 0 & 0 & 0 \\
\hline Soybean & 0 & 0 & 0 & 0 & 0 & 0 & 0 & 0 & 0 \\
\hline
\end{tabular}

a Percentage of plants out of 36 tested exhibiting Fusarium wilt within 65 days of inoculation in a replicated greenhouse experiment. Trimmed bare roots (alfalfa, clover, pea, bean, and soybean) or trimmed root masses with soil (trefoil) were soaked in a suspension of $1.0 \times 10^{6}$ spores $/ \mathrm{ml}$. Results were compared with a control treatment where root masses were soaked in dilute Czapek-Dox broth. Asterisks represent a significant difference relative to the control $(P<0.05$ and $P<0.01$ for one and two asterisks, respectively). Plants were only considered positive for Fusarium wilt if Fusarium sp. was reisolated from surface-sterilized sections of symptomatic stems collected at least $1 \mathrm{~cm}$ from the crown.

${ }^{\text {b }}$ Cultivars with known susceptibility to F. oxysporum were tested: trefoil (Lotus corniculatus) cv. Georgia-1, alfalfa (Medicago sativa) cv. MNGN-1, red clover (Trifolium pratense) cv. Chesapeake, pea (Pisum sativum) cv. M410, pinto bean (Phaseolus vulgaris) cv. U.I. 114, soybean (Glycine max) cv. Essex.

c Isolates of $F$. oxysporum f. sp. loti.

${ }^{\text {d }}$ Fom004 is an isolate of F. oxysporum f. sp. medicaginis obtained from symptomatic alfalfa in Pennsylvania; Fo062, an isolate of F. oxysporum with heightened virulence to red clover obtained from red clover in Wisconsin; Fopi001, an isolate of F. oxysporum f. sp. pisi obtained from pea in New York.

${ }^{\text {e }}$ Sterile Czapek-Dox broth diluted 1:3 with water. Czapek-Dox broth was the medium used to generate spores.

Table 3. Root necrosis a of agriculturally important legumes grown in New York after inoculation with Fusarium oxysporum isolates from birdsfoot trefoil, alfalfa, red clover, and peas

\begin{tabular}{|c|c|c|c|c|c|c|c|c|c|}
\hline \multirow[b]{2}{*}{ Host $^{\text {b }}$} & \multicolumn{5}{|c|}{ F. oxysporum f. sp. loti } & \multirow{2}{*}{$\begin{array}{c}\begin{array}{c}\text { F. oxysporum } \\
\text { f. sp. medicaginis }\end{array} \\
{\text { Fom } 004^{\mathrm{d}}}\end{array}$} & \multirow{2}{*}{$\begin{array}{c}\text { F. oxysporum } \\
\text { red clover } \\
\text { Fo062 }^{\mathrm{d}}\end{array}$} & \multirow{2}{*}{$\begin{array}{l}\begin{array}{c}\text { F. oxysporum } \\
\text { f. sp.pisi }\end{array} \\
\text { Fopi001 }^{\mathrm{d}}\end{array}$} & \multirow[b]{2}{*}{ Control $^{\mathrm{e}}$} \\
\hline & FoVt3a ${ }^{c}$ & FoVt71 ${ }^{\mathrm{c}}$ & FoMK61 & Fo069' & Fo012 $^{\mathrm{c}}$ & & & & \\
\hline Trefoil & $2.39 * * * *$ & $2.64 * * * *$ & $3.00 * * * *$ & $2.50 * * * *$ & $2.81 * * * *$ & 0.17 & 0.06 & 0.56 & 0.17 \\
\hline Alfalfa & 0.08 & 0.17 & 0.39 & 0.17 & 0 & $4.78 * * * *$ & 0.11 & 0.06 & 0.19 \\
\hline Red clover & 0.33 & 0.67 & $0.97 * *$ & 0.42 & 0.47 & $1.97 * * * *$ & $2.53 * * * *$ & $0.94 * *$ & 0.11 \\
\hline Pea & 0.47 & $1.08 *$ & $1.31 * *$ & $1.22 *$ & 0.97 & $1.08 *$ & 0.86 & $4.67 * * * *$ & 0.03 \\
\hline Bean & 0.58 & 0.47 & 0.61 & 0.56 & 0.19 & 0.53 & 0.58 & 0.67 & 0.06 \\
\hline Soybean & 0.03 & 0.08 & 0.03 & 0.03 & 0.06 & 0.03 & 0.06 & 0 & 0.06 \\
\hline
\end{tabular}

${ }^{a}$ Mean root necrosis 65 days after inoculation in a replicated greenhouse experiment; 36 plants were tested for each host-isolate combination. Trimmed bare roots (alfalfa, clover, pea, bean, and soybean) or trimmed root masses with soil (trefoil) were soaked in a suspension of $1.0 \times 10^{6}$ spores $/ \mathrm{ml}$. Root necrosis was rated on a 0 to 5 scale: 0 , no root necrosis; 1 , small dark specks or strands in the stele; 2 , moderate dark strands forming small arcs or rings in the stele cross-section; 3, large dark strands in the stele; 4, most of stele discolored; 5, stele and part or all of cortex discolored and/or plant dead. Results were compared with a control treatment where root masses were soaked in dilute Czapek-Dox broth. Asterisks represent a significant difference relative to the control $(P<0.05, P<0.01, P<0.001$, and $P<0.0001$ for one, two, three, and four asterisks, respectively).

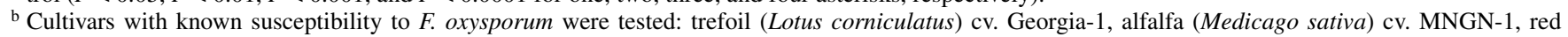
clover (Trifolium pratense) cv. Chesapeake, pea (Pisum sativum) cv. M410, pinto bean (Phaseolus vulgaris) cv. U.I. 114, soybean (Glycine max) cv. Essex.

${ }^{\mathrm{c}}$ Isolates of $F$. oxysporum f. sp. loti.

${ }^{\text {d }}$ Fom004 is an isolate of $F$. oxysporum f. sp. medicaginis obtained from symptomatic alfalfa in Pennsylvania; Fo062, an isolate of $F$. oxysporum with heightened virulence to red clover obtained from red clover in Wisconsin; Fopi001, an isolate of $F$. oxysporum f. sp. pisi obtained from pea in New York.

e Sterile Czapek-Dox broth diluted 1:3 with water. Czapek-Dox broth was the medium used to generate spores. 
(Table 2). The root necrosis response to inoculation by $F$. oxysporum isolates pathogenic to BFT was similar to the wilt response (Table 3); all five isolates pathogenic to BFT caused severe root necrosis on BFT, and three of the isolates caused moderate root necrosis on pea. One isolate also caused moderate root necrosis on red clover. Root necrosis was significantly higher than the control for all five isolates on BFT $(P<0.0001)$, for three isolates on pea $(P<0.05)$, and for one isolate on red clover $(P<0.01)$. The $F$. oxysporum isolates pathogenic to alfalfa, red clover, and pea caused severe root necrosis and moderate to high incidence of vascular wilt on their respective hosts but not on BFT, bean, or soybean (Tables 2 and 3). The isolate pathogenic to alfalfa caused higher root necrosis on red clover and on pea relative to the control $(P<0.05)$; the isolates pathogenic to pea and to red clover caused a low incidence of vascular wilt on pea that was not significantly different from the control $(P>0.05)$. The isolate pathogenic to pea caused a low incidence of vascular wilt on BFT not significantly different from the control $(P>0.05)$. In the control, root necrosis was low, but one plant developed vascular wilt (Tables 2 and 3).

Vegetative compatibility. All isolates pathogenic to BFT were vegetatively com-
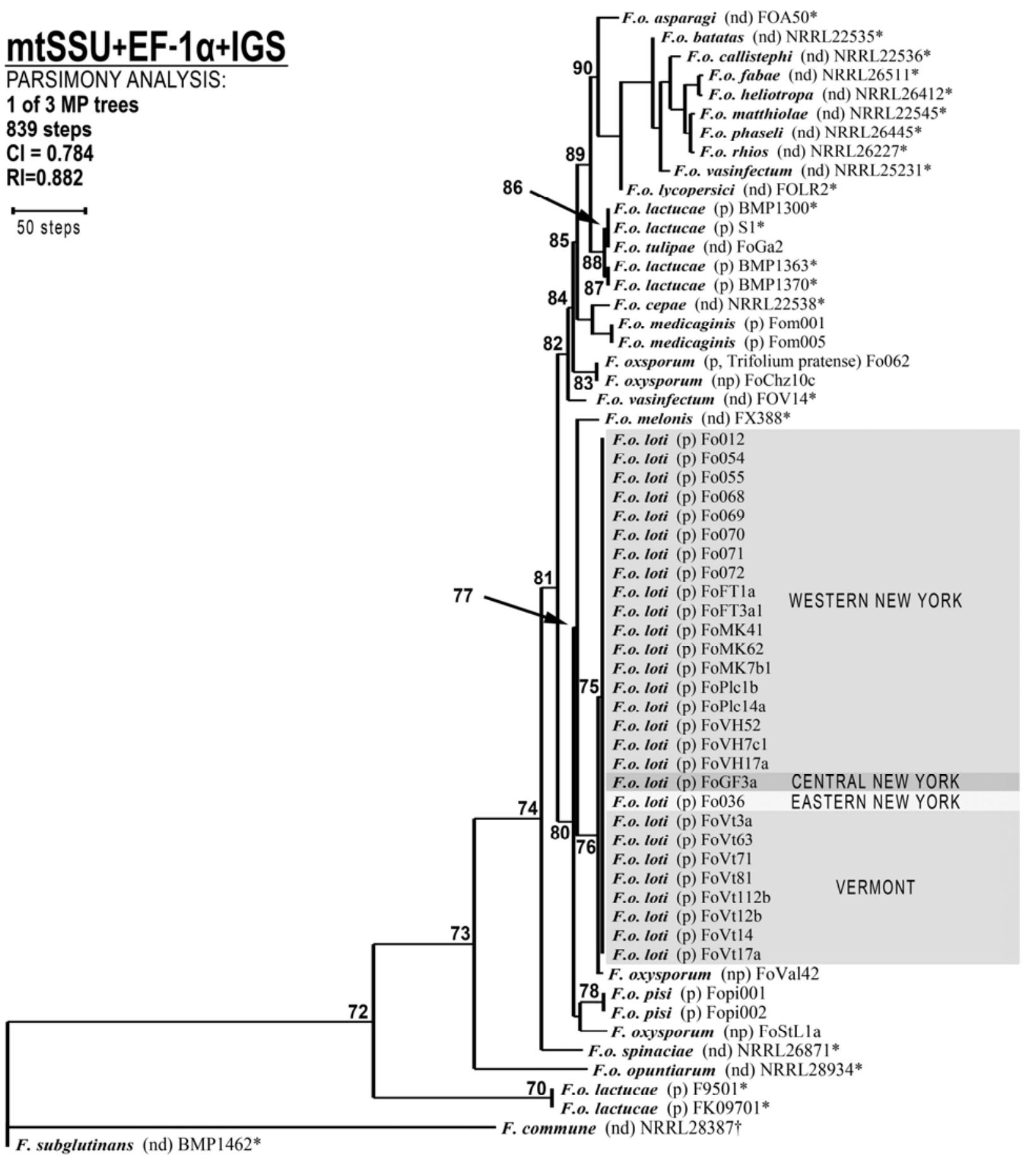

Fig. 1. Maximum parsimony analysis of the concatenated mitochondrial small subunit rDNA (mtSSU), elongation factor 1-alpha (EF-1 $\alpha$ ), and intergenic spacer (IGS) partitions rooted with Fusarium subglutinans isolate BMP1462. Shown is one of three most parsimonious trees; parsimony bootstrap values greater than 70\% (1,000 replications) are indicated at the internodes. Isolates tested for pathogenicity in this study or in Mbofung et al. (34) and found to be pathogenic or nonpathogenic are denoted with "(p)" or "(np)", respectively; isolates not tested for pathogenicity are denoted with "(nd)". Isolates sequenced by Mbofung et al. (34) are noted with an asterisk, and isolates sequenced by Baayen et al. (7) or K. O'Donnell are noted by the symbol “†”; all other isolates were sequenced in this study. 
patible. Reciprocal pairwise crosses between NitM and nitl mutants of isolates Fo036, Fo068, FoMK41, FoPlc14a, FoVH17a, FoVt63, FoChz10c, FoStL1a, and FoVal42 produced heterokaryons only between mutants of pathogenic isolates and between mutants of the same isolate. Four VCGs were identified; all pathogenic isolates shared a single VCG, and nonpathogenic isolates each represented unique VCGs. All isolates were selfcompatible. Crosses between nitl mutants of the remaining 22 pathogenic isolates and Fo036, FoChz10c, FoStL1a, and FoVal42 NitM tester strains (representing each of the four VCGs) resulted in heterokaryon formation only with the Fo036 NitM tester strain. Nitl mutants of each of the remaining 22 pathogenic isolates were compatible with the Fo036 NitM tester strain; none were compatible with the FoChz10c, FoStL1a, or FoVal42 NitM tester strains. All pathogenic isolates were assigned to a single VCG distinct from the VCGs represented by the nonpathogenic isolates (Table 1). The VCG of the pathogenic isolates was assigned VCG code 0480 by T. R. Gordon (University of California, Davis), the current $F$. oxysporum VCG numbering coordinator, in accordance with the numbering system proposed by Puhalla (43), Kistler et al. (29), and Katan (25).

Phylogenetic analysis. Amplification of the mtSSU, EF- $1 \alpha$, and IGS regions resulted in PCR products approximately 730 , 700 , and 3,100 bp long, respectively. All of the isolates pathogenic to BFT shared identical sequence at the mtSSU, EF- $1 \alpha$, and IGS loci.

The aligned mtSSU, EF-1 $\alpha$, and IGS data sets consisted of 714, 695, and 2,565 characters, respectively, of which 17,38 , and 220 characters, respectively, were parsimony-informative. Maximum parsimony analysis of the concatenated sequences resulted in three MPTs with 839 steps $(\mathrm{CI}=0.784, \mathrm{RI}=0.882)$. The MPTs differed with respect to the placement of nonpathogenic isolate FoStL1a obtained from BFT and the subclade containing $F$. oxysporum f. sp. pisi isolates Fopi001 and Fopi002. Isolates pathogenic to BFT plus one nonpathogenic isolate were placed in a clade $(76 \%$ bootstrap support) distinct from isolates pathogenic to other hosts (Fig. 1). The isolates pathogenic to BFT were placed in a single subclade $(75 \%$ bootstrap support); no other isolates were in the clade (Fig. 1).

\section{DISCUSSION}

We propose that the fungus causing Fusarium wilt of BFT be designated Fusarium oxysporum Schlechtendahl emend. Snyder \& Hansen f. sp. loti forma specialis nov., as suggested by Bergstrom and Kalb (9). Among legumes of economic importance in New York, the fungus displays a unique host range, causing severe vascular wilt of BFT but not of alfalfa, red clover, dry bean, or soybean. None of the other pathogenic $F$. oxysporum tested caused vascular wilt of BFT. A single BFT plant inoculated with $F$. oxysporum f. sp. pisi developed vascular wilt, but because wilt developed in only one replicate of the experiment, cross-contamination likely caused this result.

The host range of $F$. oxysporum f. sp. loti may extend to pea. All five isolates of the BFT pathogen tested caused vascular wilt of pea, with four of the five isolates causing vascular wilt in at least two of the three replicates of the experiment. A host range encompassing both $\mathrm{BFT}$ and pea would not be surprising; many formae speciales of $F$. oxysporum, including vasinfectum, apii, and medicaginis, are known to cause vascular wilt on multiple hosts (6). However, additional experiments will be needed to confirm this result. Low levels of vascular wilt were also observed in pea inoculated with $F$. oxysporum isolates pathogenic to alfalfa and red clover, and it is likely that the inoculation technique used for peas was unduly harsh and predisposed plants to infection. Disease development associated with $F$. oxysporum can depend on inoculation technique (5), and the host range exhibited by the pathogen under field conditions in naturally infested soils could be different.

$F$. oxysporum f. sp. loti is a monophyletic pathogen composed of a single clonal lineage. All $F$. oxysporum f. sp. loti isolates collected across New York and Vermont over a 20-year period were vegetatively compatible, shared identical mtSSU, EF- $1 \alpha$, and IGS sequence haplotypes, and were placed into a single, wellsupported clade by maximum parsimony analysis. In $F$. oxysporum, isolates belonging to the same VCG are traditionally interpreted as descendants of a common ancestor (30). Sexual recombination, which could shuffle heterokaryon incompatibility alleles and obscure the relationship between VCG and evolutionary lineage, is not known to occur in F. oxysporum (19), and meiotic and/or mitotic recombination, if present, are believed to be rare events. That $F$. oxysporum f. sp. loti is a monophyletic pathogen characterized by a single clonal lineage is not surprising. Other formae speciales, including albedinis and ciceris $(24,48)$, have been reported with a similar population structure.

Wilt diseases caused by $F$. oxysporum are generally managed by host resistance. Related species of Lotus may be valuable sources of resistance to Fusarium wilt for improvement of BFT. Three cultivars (Columbia, Maku, and Marshfield) of L. uliginosus were highly resistant, and one accession (PI 316270) of L. glaber was moderately resistant to a New York isolate of $F$. oxysporum from BFT (11; unpublished data). Zeiders and Hill (57) demonstrated that the potential for development of resistant lines exists within the gene pool of L. corniculatus. Pardee, a BFT cultivar with moderate resistance to Fusarium wilt, has recently been registered (52) and may provide an alternative to growers interested in planting BFT in fields with a history of Fusarium wilt. Because of the observed clonality of $F$. oxysporum $\mathrm{f}$. sp. loti, the current study suggests this cultivar, which was developed using a single isolate of the pathogen to screen for resistance, may exhibit moderate resistance to Fusarium wilt throughout the known geographic range of the disease. However, breeders should be cautious in interpreting the apparent clonality of $F$. oxysporum f. sp. loti within the context of virulence; high genetic similarity of $F$. oxysporum isolates does not necessarily preclude the existence of race-level variability $(17,24,35)$.

To date, the occurrence of Fusarium wilt of BFT and of the pathogen F. oxysporum f. sp. loti is known only in New York and Vermont. Movement of infected trefoil hay and infested soil are the most likely mechanisms for geographic spread of the pathogen. Based on inoculation of flowering BFT plants, Litchfield-Kimber (33) demonstrated that $F$. oxysporum f. sp. loti did not infect seed, but that seed lots artificially contaminated with dry fragments of infected pods and other vegetative tissues could serve to disseminate the viable pathogen. Yet she did not detect the Fusarium wilt pathogen in commercial BFT seed lots produced in Michigan, Minnesota, western New York, or Wisconsin, or in Alberta, Canada (33). The fungal gene sequence and vegetative compatibility tools identified in this study should prove useful in detecting $F$. oxysporum f. sp. loti in plants and soil and in tracking any future expansion in the pathogen's geographic range. We have designated isolate Fo069 as the type culture for $F$. oxysporum f. sp. loti and deposited it with the American Type Culture Collection (Manassas, VA). Isolates Fo069, FoMK61, and FoVt63 have also been deposited in the culture collection of the Fusarium Research Center at the Pennsylvania State University (State College, PA).

\section{ACKNOWLEDGMENTS}

This research was supported in part by Cornell University Hatch Project NYC153433, by a 1year research grant from the New York State Integrated Pest Management Program, and by a 1year graduate student assistantship to the senior author from the Cornell University Department of Plant Pathology. Ameena Nalim and Bruce Tillapaugh are gratefully acknowledged for preliminary inoculation studies on this fungus. We thank Donald Viands and Julie Hansen for their advice on these studies and their help in acquiring seed of BFT cultivars. We also thank Carl Albers, Peter Barney, Tom Kilcer, and Bruce Tillapaugh of Cornell Cooperative Extension, Everett Thomas of the W.H. Miner Agricultural Research Institute, and Jeff Carter of University of Vermont Extension for their assistance in surveys of BFT production fields. 


\section{LITERATURE CITED}

1. Altier, N. 1997. Epidemiological and ecological studies on Fusarium crown and root diseases of birdsfoot trefoil in Uruguay, and the prospects for breeding for resistance. Ph.D. thesis. University of Minnesota, St. Paul, MN.

2. Altier, N. 1997. Enfermedades del Lotus en Uruguay. Serie Técnica 93. Instituto Nacional de Investigación Agropecuaria, Montevideo, Uruguay.

3. Altier, N., Ehlke, N. J., and Rebuffo, M. 2000. Divergent selection for resistance to Fusarium root rot in birdsfoot trefoil. Crop Sci. 40:670675.

4. Anderson, J. B., and Stasovski, E. 1992. Molecular phylogeny of northern hemisphere species of Armillaria. Mycologia 84(4):505-516.

5. Armstrong, G. M., and Armstrong, J. K. 1975. Reflections on the wilt fusaria. Annu. Rev. Phytopathol. 13:95-103.

6. Armstrong, G. M., and Armstrong, J. K. 1981. Formae speciales and races of Fusarium oxysporum causing wilt disease. Pages 391-399 in: Fusarium: Diseases, Biology and Taxonomy. P. E. Nelson, T. A. Toussoun, and R. J. Cook, eds. The Pennsylvania State University Press, University Park.

7. Baayen, R. P., O’Donnell, K., Bonants, P. J. M., Cigelnik, E., Kroon, L. P. N. M., Roebroeck, E. J. A., and Waalwijk, C. 2000. Gene genealogies and AFLP analyses in the Fusarium oxysporum complex identify monophyletic and nonmonophyletic formae speciales causing wilt and rot disease. Phytopathology 90:891-900.

8. Berkenkamp, B., Folkins, L., and Meeres, J. 1972. Crown and root rot of birdsfoot trefoil in Alberta. Can. Plant Dis. Surv. 52(1):1-3.

9. Bergstrom, G. C., and Kalb, D. W. 1995. Fusarium oxysporum f. sp. loti: A specific wilt pathogen of birdsfoot trefoil in New York. (Abstr.) Phytopathology 85:1555.

10. Bergstrom, G. C., and Kalb, D. W. 1995. Susceptibility of birdsfoot trefoil cultivars to Fusarium oxysporum f. sp. loti. Page 8 in: American Society of Agronomy Northeastern Branch Abstracts July 14-17, 1996, Cornell University, Ithaca, NY. American Society of Agronomy, Madison, WI.

11. Bergstrom, G. C., Kalb, D. W., Tillapaugh, B. P., and Lucey, R. F. 1995. Fusarium wilt of birdsfoot trefoil: Biology and prospects for management. Pages 43-44 in: Proc. Eastern Forage Improvement Conf., 11th. July 6-8, 1995. Ottawa, Ontario, Canada.

12. Brumrner, J. E., and Nygaard, S. L. 1995. Fusarium wilt resistance - Greenhouse/ Controlled Environment. Standard Tests to Characterize Alfalfa Cultivars. http://www. naaic.org

13. Chao, L., de Battista, J. P., and Santinaque, F. 1992. A survey of diseases affecting Lotus corniculatus in West Uruguay and Entre Rios Province (Argentina). Lotus Newsl. 23:61-62.

14. Chevrette, J. E., Folkins, L. P., Gauthier, F. M., and Greenshields, J. E. R. 1960. Evaluation of birdsfoot trefoil I. Compatibility of Lotus corniculatus L. with other legumes and grasses. Can. J. Plant Sci. 40:259-267.

15. Correll, J. C., Klittich, C. J. R., and Leslie, J. F. 1987. Nitrate nonutilizing mutants of Fusarium oxysporum and their use in vegetative compatibility tests. Phytopathology 77:16401646.

16. Drake, C. R. 1958. Diseases of birdsfoot trefoil in six southeastern states in 1956-7. Plant Dis. Rep. 42:145-146.

17. Elias, K. S., Zamir, D., Lichtman-Pleban, T., and Katan, T. 1993. Population structure of Fusarium oxysporum f. sp. lycopersici: Restriction fragment length polymorphisms provide genetic evidence that vegetative compatibility group is an indicator of evolutionary origin. Mol. PlantMicrobe Interact. 6:565-572.
18. Ferrant, N. P., and Carroll, R. B. 1981. Fusarium wilt of soybean in Delaware. Plant Dis. 65:596-599.

19. Gordon, T. R., and Martyn, R. D. 1997. The evolutionary biology of Fusarium oxysporum. Annu. Rev. Phytopathol. 35:111-128.

20. Gordon, T. R., Okamoto, D., and Jacobson, D. J. 1989. Colonization of muskmelon and nonsusceptible crops by Fusarium oxysporum f. sp. melonis and other species of Fusarium. Phytopathology 79:1095-1100.

21. Gotlieb, A. R., and Doriski, H. 1983. Fusarium wilt of birdsfoot trefoil in Vermont and New York. (Abstr.) Phytopathology 73:366.

22. Heinrichs, D. H. 1970. Flooding tolerance of legumes. Can. J. Plant Sci. 50:435-438.

23. Hosmer, D. W., and Lemeshow, S. 2000. Applied Logistic Regression. John Wiley \& Sons, New York.

24. Jiménez-Gasco, M. M., Milgroom, M. G., and Jiménez-Díaz, R. M. 2002. Gene genealogies support Fusarium oxysporum f. sp. ciceris as a monophyletic group. Plant Pathol. 51:72-77.

25. Katan, T. 1999. Current status of vegetative compatibility groups in Fusarium oxysporum. Phytoparasitica 27(1):51-64.

26. Keeney, D. 1985. Edaphic limitations and soil nutrient requirements of legume-based forage systems in the temperate United States. Pages 95-100 in: Proc. Forage Legumes for EnergyEfficient Anim. Prod., Palmerston North, New Zealand, 30 April-4 May 1984. R. F. Barnes, P. R. Ball, R. W. Brougham, G. C. Marten, and D. J. Minson, eds. U.S. Dep. Agric.-Agric. Res. Serv., Washington DC.

27. Kendall, W. A. 1966 . Factors affecting foams with forage legumes. Crop Sci. 6:487-489.

28. Kim, Y., Hutmacher, R. B., and Davis, R. M. 2005. Characterization of California isolates of Fusarium oxysporum f. sp. vasinfectum. Plant Dis. 89:366-372.

29. Kistler, H. C., Alabouvette, C., Baayen, R. P., Bentley, S., Brayford, D., Coddington, A., Correll, J., Daboussi, M.-J., Elias, K., Fernandez, D., Gordon, T. R., Katan, T., Kim, H. G., Leslie, J. F., Martyn, R. D., Migheli, Q., Moore, N. Y., O'Donnell, K., Ploetz, R. C., Rutherford, M. A., Summerell, B., Waalwijk, C., and Woo, S. 1998. Systematic numbering of vegetative compatibility groups in the plant pathogenic fungus Fusarium oxysporum. Phytopathology 88:30-32.

30. Klein, K. K., and Correll, J. C. 2001. Vegetative compatibility group diversity in Fusarium. Pages 83-96 in: Fusarium, Paul E. Nelson Memorial Symposium. B. A. Summerell, J. F. Leslie, D. Blackhouse, W. L. Bryden, and L. W. Burgess, eds. American Phytopathological Society, St. Paul, MN

31. Koenig, R. L., Ploetz, R. C., and Kistler, H. C. 1997. Fusarium oxysporum f. sp. cubense consists of a small number of divergent and globally distributed clonal lineages. Phytopathology 87:915-923.

32. Kraft, J. M. 1994. Fusarium wilt of peas (a review). Agronomie 14:561-567.

33. Litchfield-Kimber, L. 1996. Fusarium wilt of birdsfoot trefoil: Pathogen introduction and interaction with nematodes. M.S. thesis. Cornell University, Ithaca, NY.

34. Mbofung, G. Y., Hong, S. G., and Pryor, B. M. 2007. Phylogeny of Fusarium oxysporum f. sp. lactucae inferred from mitochondrial small subunit, elongation factor $1-\alpha$, and nuclear ribosomal intergenic spacer sequence data. Phytopathology 97:87-98.

35. Mes, J. J., van Doorn, J., Roebroeck, E. J. A., van Egmond, E., van Aartrijk, J., and Boonekamp, P. M. 1994. Restriction fragment length polymorphisms, races and vegetative compatibility groups within a worldwide collection of Fusarium oxysporum f. sp. gladioli. Plant Pathol. 43:362-370.

36. Murphy, W. M., Gotlieb, A. R., and Dugdale,
D. T. 1985. The effects of Fusarium wilt and weed control on survival of birdsfoot trefoil. Can. J. Plant Sci. 65:329-334.

37. Nelson, P. E., Toussoun, T. A., and Marasas, W. F. O. 1983. Fusarium Species: An Illustrated Manual for Identification. Pennsylvania State University, University Park.

38. Neter, J., Kutner, M. H., Nachtscheim, C. J., and Wasserman, W. 1996. Applied Linear Statistical Models, 3rd ed. McGraw Hill, Boston, MA.

39. O'Donnell, K., Kistler, H. C., Cigelnik, E., and Ploetz, R. C. 1998. Multiple evolutionary origins of the fungus causing Panama disease of banana: Concordant evidence from nuclear and mitochondrial gene genealogies. Proc. Natl. Acad. Sci. USA 95:2044-2049.

40. O'Donnell, K., Sutton, D. A., Rinaldi, M. G., Magnon, K. C., Cox, P. A., Revankar, S. G., Sanche, S., Geiser, D. M., Juba, J. H., van Burik, J. H., Padhye, A., Anaissie, E. J. Francesconi, A., Walsh, T. J., and Robinson, J. S. 2004. Genetic diversity of human pathogenic members of the Fusarium oxysporum complex inferred from multilocus DNA sequence data and amplified fragment length polymorphism analyses: Evidence for the recent dispersion of a geographically widespread clonal lineage and nosocomial origin. J. Clin. Microbiol. 42:5109-5120.

41. Pastor-Corrales, M. A., and Abawi, G. S. 1987 Reactions of selected bean germ plasms to infection by Fusarium oxysporum f. sp. phaseoli. Plant Dis. 71:990-993.

42. Ploetz, R. C., and Pegg, K. G. 2000. Fusarium wilt. Pages 143-149 in: Diseases of Banana, Abacá and Enset. D. R. Jones, ed. CABI Publishing, Wallingford, UK.

43. Puhalla, J. E. 1985. Classification of strains of Fusarium oxysporum on the basis of vegetative compatibility. Can. J. Bot. 63:179-183.

44. Salgado, M. O., Schwartz, H. F., Brick, M. A., and Pastor-Corrales, M. A. 1994. Resistance to Fusarium oxysporum f. sp. phaseoli in tepary beans (Phaseolus acutifolius). Plant Dis. 78:357-360.

45. Sandler, H. A., Carroll, R. B., and Sparks, D. L. 1988. Effect of Biocidal Treatments on Cation Exchange Capacity and Fusarium Blight of Soybean in Delaware Soils. Agron. J 80:8-12.

46. Skovgaard, K., Nirenberg, H. I., O’Donnell, K., and Rosendahl, S. 2001. Evolution of Fusarium oxysporum f. sp. vasinfectum races inferred from multigene genealogies. Phytopathology 91:1231-1237.

47. Swofford, D. L. 2002. PAUP*. Phylogenetic analysis using parsimony (* and other methods), version 4. Sinauer Associates, Sunderland, MA.

48. Tantaoui, A., Ouinten, M., Geiger, J.-P., and Fernandez, D. 1996. Characterization of a single clonal lineage of Fusarium oxysporum f. sp. albedinis causing bayoud disease of date palm in Morocco. Phytopathology 86:787-792.

49. Terrill, T. H., Rowan, A. M., Douglas, G. B. and Barry, T. N. 1992. Determination of extractable and bound condensed tannin concentrations in forage plants, protein concentrate meals and cereal grains. J. Sci. Food Agric. 58:321-329.

50. Tillapaugh, B. P. 1991. Assessment of cultural practices and diseases affecting the establishment and persistence of Norcen birdsfoot trefoil (Lotus corniculatus L.) in western New York. M.S. thesis. Cornell University, Ithaca, NY.

51. Venuto, B. C., Smith, R. R., and Grau, C. R 1995. Virulence, legume host specificity, and genetic relatedness of isolates of Fusarium ox ysporum from red clover. Plant Dis. 79:406410.

52. Viands, D. R., Miller-Garvin, J. E., Hansen, J. 
L., Bergstrom, G. C., Tillapaugh, B. P., Lowe, C. C., Thomas, E. M., and Neally, J. L. 2004. Registration of 'Pardee' birdsfoot trefoil. Crop Sci. 44(4):1488-1489.

53. Wang, B., and Jeffers, S. N. 2000. Fusarium root and crown rot: A disease of containergrown hostas. Plant Dis. 84:980-988.

54. White, T. J., Bruns, T., Lee, S., and Taylor, J.
1990. Amplification and direct sequencing of fungal ribosomal RNA genes for phylogenetics. Pages 315-322 in: PCR Protocols: A Guide to Methods and Applications. M. A. Innis, D. H. Gelfand, J. J. Sninsky, and J. W. White, eds. Academic Press, New York.

55. Windels, C. E., and Kommedahl, T. 1974. Population differences in indigenous Fusarium species by corn culture of prairie soil. Am. J. Bot. 61(2):141-145.

56. Zar, J. H. 1999. Biostatistical Analysis, 4th ed. Prentice Hall, Upper Saddle River, NJ.

57. Zeiders, K. E., and Hill, R. R. 1988. Measurement of resistance to Fusarium wilt/root and crown rot in birdsfoot trefoil populations. Crop Sci. 28:468-473. 